\title{
The Influence Law of Oil Relative Permeability on Water Cut
}

\author{
Yanhui Zhang*, Yingxian Liu, Hongyou Zhang, Mengjun Bie, Guangyi Sun \\ Bohai Oilfield Research Institute, CNOOC China Limited, Tianjin Branch, Tianjin, China \\ Email: *zhangyh27@cnooc.com.cn
}

How to cite this paper: Zhang, Y.H., Liu, Y.X., Zhang, H.Y., Bie, M.J. and Sun, G.Y. (2018) The Influence Law of Oil Relative Permeability on Water Cut. Journal of Geoscience and Environment Protection, 6, 223-232.

https://doi.org/10.4236/gep.2018.69017

Received: August 29, 2018

Accepted: September 27, 2018

Published: September 30, 2018

Copyright $\odot 2018$ by authors and Scientific Research Publishing Inc. This work is licensed under the Creative Commons Attribution International License (CC BY 4.0).

http://creativecommons.org/licenses/by/4.0/

\begin{abstract}
Water cut is a key evaluation parameter for reservoir development evaluation. Relative permeability curve reflects reservoir characteristics and fluid characteristics. It is important to figure out the influence law of oil relative permeability on water cut. Based on the 269 relative permeability curves of Bohai oilfields, the distribution of oil index of Bohai oilfields were studied. On the basis, combined with Corey expression of relative permeability and fractional flow equation, the theoretical relationship between oil index and water cut increasing rate was established. Three end points of water cut increasing rate curve were proposed and the influence law between three end points and oil index was studied. The results show that the oil index has a linear relationship with three end points. When the value of water oil mobile ratio is large than 1 , with the increase of oil index, maximum value of water cut increasing rate gradually increase. When the value of water oil mobile ratio is less than 10, oil index has great effect on recovery percent when water cut increasing rate reaches to the maximum value as well as water cut when water cut increasing rate reaches to the maximum value. The application of SS field shows that the theoretical value is consistent with the field data.
\end{abstract}

\section{Keywords}

Water Cut Increasing Rate, Oil Relative Permeability, Oil index, End Point of Relative Permeability Curve

\section{Introduction}

Water cut is a key evaluation parameter for reservoir development evaluation. There are many factors affecting water cut. Generally, geological factors and dynamic factors are the two main classes. Relative permeability curve reflects reservoir characteristics and fluid characteristics [1] [2]. So, relative permeability 
curve is one of the main factors affecting water cut [3]. However the influence law of relative permeability on water cut is very complex. Analytical method and reservoir simulation method are the two mostly used methods [4] [5]. Because of the simple and convenient characteristics, analytical methods are used by more and more engineers. Relative permeability of oil phase and water phase can be described in many ways, among them Corey expression is widely adopted by reservoir engineers. Zhang Jinqing proposed the expression of the decline rate under the condition of fixed liquid volume [6]. Based on this, Miao Feifei gave the calculation method of the decline rate under the conditions of constant liquid volume and constant pressure difference [7]. Liu yingxian proposed a new calculating method of theoretical decline law for water flooding sandstone reservoir based on relative permeability [8]. Besides, the theoretical relationship curve between the water cut and recovery percent was be built by some engineers [9].

Water index and oil index can directly reflect the shape of relative permeability, so the influence of water index and oil index on water cut increasing rate is very important. Wang Shuguang built the statistical regularity of oil-water relative permeability of Daqing oilfield [10]. Shang Liping deduced the natural decline rate of old wells under different production time and water production rate according to the relative permeability curve of oil phase [11]. How oil index effect water cut increasing rate and how the distribution of oil index of actual reservoirs are, there has rare papers reported.

Based on the 269 relative permeability curves of Bohai oilfields, the distribution of oil index of Bohai oilfields were studied. Based on Corey expression of relative permeability and fractional flow equation, the relationship between oil index and water cut increasing rate was established. The three end points of theoretical curve of water cut increasing rate were proposed and the influence law between three end points and oil index was studied.

\section{Theory and Methodology}

\subsection{The Statistical Law of Oil Index}

Relative permeability of oil phase and water phase can be described in many ways, among them Corey expression is widely adopted by reservoir engineers [12].

$$
\begin{gathered}
K_{r w}=K_{r w}\left(S_{o r}\right) S_{w d}^{n_{w}} \\
K_{r o}=K_{r o}\left(S_{w i}\right)\left(1-S_{w d}\right)\left(1-S_{w d}\right)^{n_{o}} \\
S_{w d}=\frac{S_{w}-S_{w i}}{1-S_{w i}-S_{o r}}
\end{gathered}
$$

where $K_{r w}$ is water relative permeability; $K_{r w}\left(S_{o r}\right)$ is water relative permeability at residual oil saturation; $S_{w d}$ is normalized water saturation; $n_{w}$ is water index; $K_{r o}$ is oil relative permeability; $K_{r o}\left(S_{w i}\right)$ is oil relative permeability at 
irreducible water saturation; $S_{w i}$ is irreducible saturation; $n_{o}$ is oil index; $S_{w}$ is average water saturation.

The logarithm expression of Equation (1) and Equation (2) are as follows:

$$
\begin{gathered}
\lg \left(K_{r w} / K_{r w}\left(S_{o r}\right)\right)=n_{w} \lg \left(S_{w d}\right) \\
\lg \left(K_{r o} /\left(K_{r o}\left(S_{w i}\right)\left(1-S_{w d}\right)\right)\right)=n_{o} \lg \left(S_{w d}\right)
\end{gathered}
$$

According to Equation (5), the oil index can be calculated. 269 relative permeability curves of Bohai oilfied was processed according to this method and the logarithm data of oil relative permeability are as shown in Figure 1.

As can be seen form Figure 1, the average oil index of Bohai oilfied is 2.51. Further, the oil index of these curves was calculated, according to this method (Figure 2). As can be seen form Figure 2, the oil index mostly distributes in the range of $2.0-3.0$.

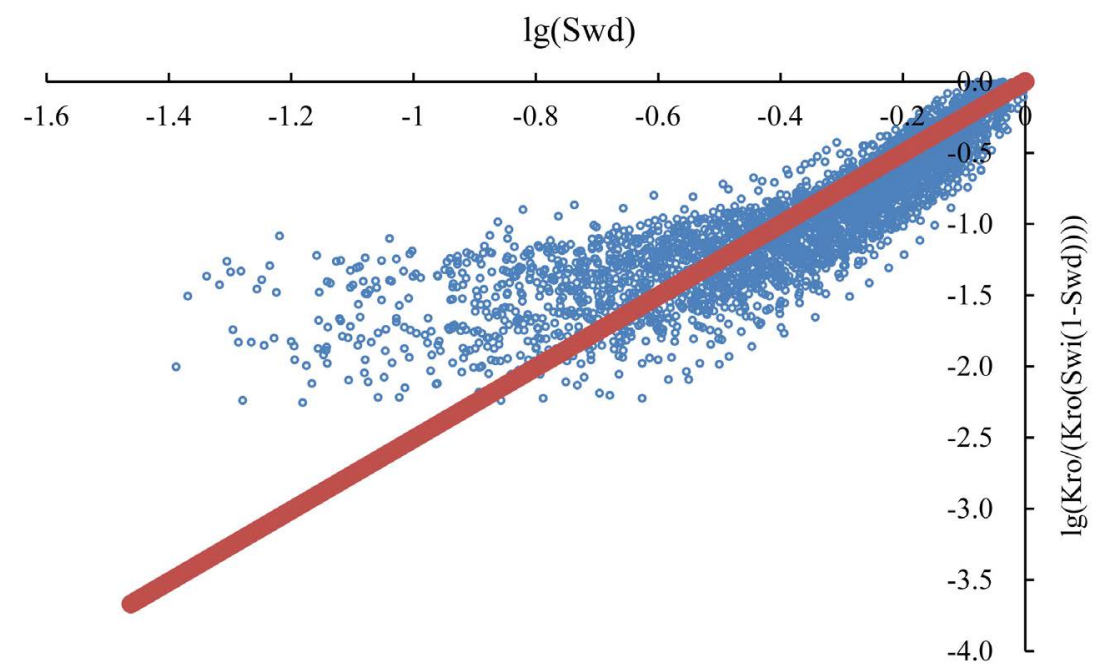

Figure 1. The logarithm data of oil relative permeability of Bohai oilfield.

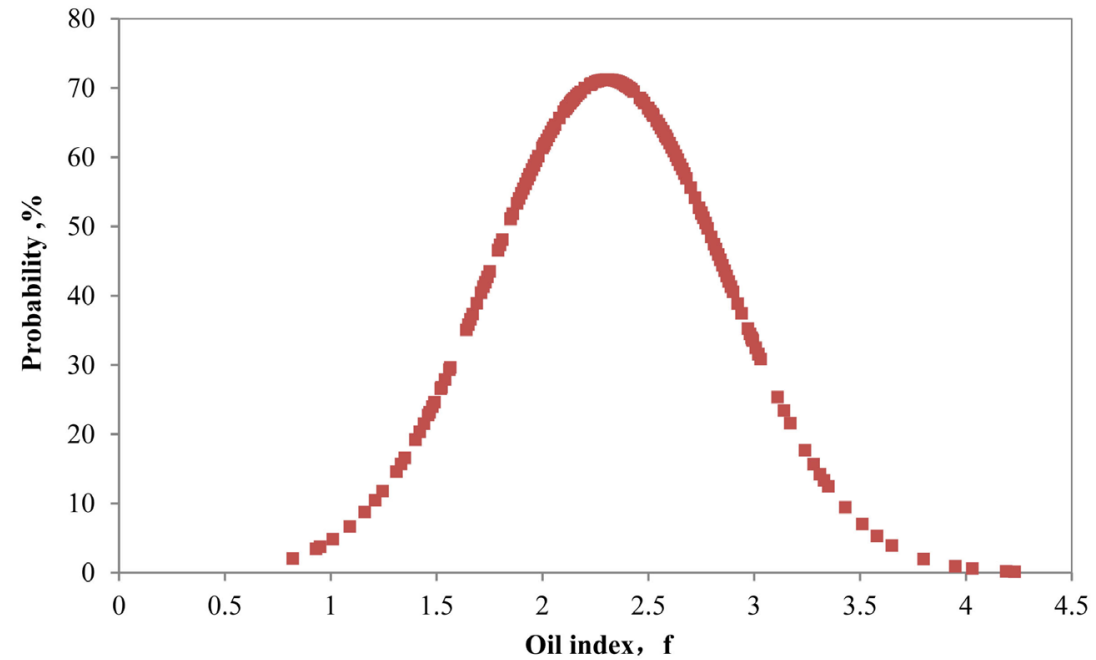

Figure 2. The probability distribution curve of oil index of Bohai oilfield. 


\subsection{The Relationship between Oil Index and Water Cut}

Water-oil mobility ratio can be defined as:

$$
M=\frac{\mu_{o} B_{o} K_{r w}\left(S_{o r}\right)}{\mu_{w} B_{w} K_{r o}\left(S_{w i}\right)}
$$

where $M$ is water-oil mobility ratio; $f_{w}$ is water cut; $\mu_{w}$ is formation viscosity, $\mathrm{mPa} \cdot \mathrm{s} ; B_{w}$ is formation water volume factor; $B_{o}$ is formation oil volume factor.

Based on fractional flow equation, water cut can be described as follows:

$$
f_{w}=\frac{M S_{w d}^{n_{w}}}{M S_{w d}^{n_{w}}+\left(1-S_{w d}\right)^{n_{o}}}
$$

where $f_{w}$ is water cut.

According to the definition of normalized water saturation, normalized water saturation can be described as follows:

$$
S_{w d}=\frac{1-S_{w i}}{1-S_{w i}-S_{o r}} R=k R
$$

where $R$ is recovery percent of geologic reservoir; $k$ is constant.

Combined with above equation water cut can be expressed as:

$$
f_{w}=\frac{M(k R)^{n_{w}}}{M(k R)^{n_{w}}+(1-k R)^{n_{o}}}
$$

According to the definition of water cut increasing rate, water cut increasing rate can be expressed as:

$$
f_{w}^{\prime}=\frac{M(k R)^{n_{w}-1}(1-k R)^{n_{o}-1}\left[n_{w}(1-k R)+n_{o} k R\right]}{\left[M(k R)^{n_{w}}+(1-k R)^{n_{o}}\right]^{2}}
$$

\subsection{The Effect of Water Index on Water Cut Increasing Rate}

In order to study the effect of oil index on water cut increasing rate, we designed many projects with different oil index on the condition that other influencing factors keeps constant. The parameters of basic project is as shown in Table 1.

Table 1. The parameters of basic project.

\begin{tabular}{cc}
\hline Parameters & Value \\
\hline Irreducible water saturation, f & 0.289 \\
Residual oil saturation, f & 0.215 \\
Water index & 2.00 \\
Oil index & $1.5,2.0,2.5,3.0$ \\
Porosity & 0.30 \\
Water oil mobility raio & 10 \\
Water relative permeability at residual oil saturation & 0.41 \\
Oil relative permeability at irreducible water saturation & 1.00
\end{tabular}


The oil relative permeability with different oil index are shown in Figure 3. As can be seen form Figure 3, with the increase of oil index, oil relative permeability curve became more and more concave. That is to say, with the increase of oil index, oil relative permeability curve decrease more and more sharply.

The relation curve water cut increasing rate and water cut, water cut increasing rate and recovery percent $(R)$ are shown respectively in Figure 4(a) and Figure 4(b). As can be seen from Figure 4(a), with the increase of oil index, the relation curve between water cut increasing rate and water cut gradually deviate to right and the maximum value of water cut increasing rate become more and more bigger. As can be seen from Figure 4(b), with the increase of oil index, the maximum value of water cut increasing rate become more and more bigger. Besides, with the increase of oil index, water cut increasing rate increase more and more sharply during its rising stage and decrease more and more sharply during its falling stage.

\section{Results}

\subsection{The Variation Law of End Points of Water Cut Increasing Rate Curve}

Three end points were proposed to describe the curve shape of water cut in

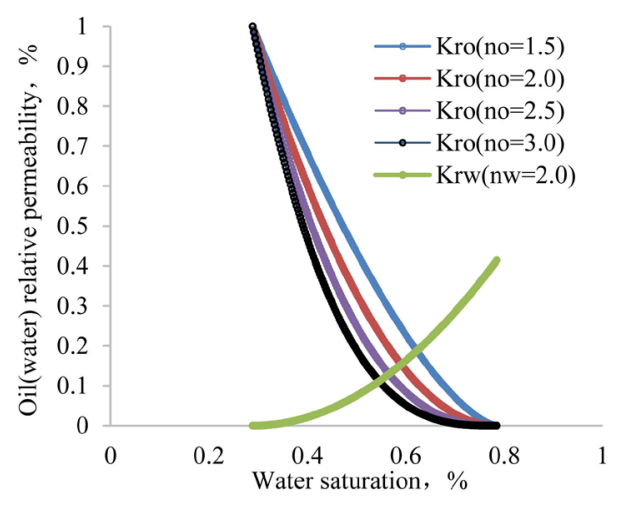

Figure 3. The different oil relative permeability under the condition of different oil index.

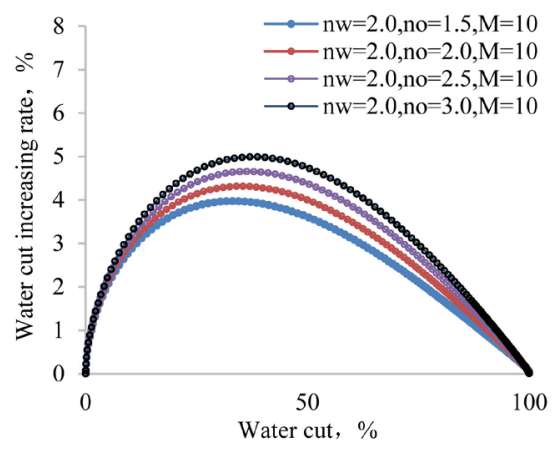

(a)

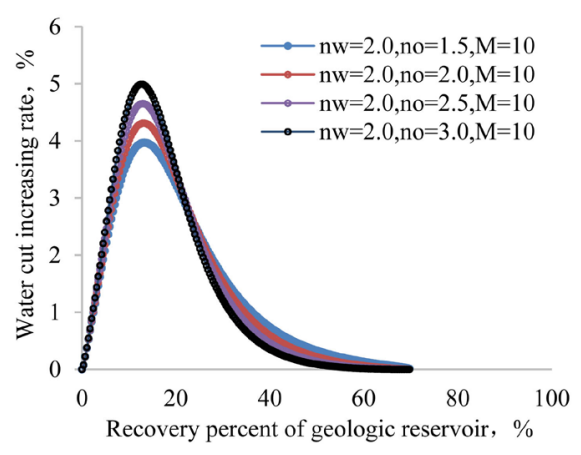

(b)

Figure 4. The water cut increasing rate under the condition of different oil index. (a) Water cut increasing rate VS water cut; (b) Water cut increasing rate VS recovery percent. 
creasing rate. The three parameters are the maxima value of water cut increasing rate, the water cut when water cut increasing rate reaches to the maximum value and the recovery degree when water cut increasing rate reaches to the maximum value.

The relation curve between this three end points and oil index are respectively shown in Figures 5(a)-(c).

As can be seen from Figure 5(a), there is a linear relationship between maximum values of water cut increasing rate and oil index. When the value of water oil mobile ratio is large than 1 , with the increase of oil index, maximum value of water cut increasing rate gradually increase. With the increase of oil index, the curve shape of oil relative permeability is more concave, so the oil relative permeability decrease more and more sharply and the water cut increase more and more fast. When the value of water oil mobile ratio is less than 1 , with the increase of oil index, maximum value of water cut increasing rate gradually decrease.

As can be seen from Figure 5(b), there is a linear relationship between water cut when water cut increasing rate reaches to the maximum value and oil index. When the value of water oil mobile ratio is less than 10, oil index has great effect on water cut when water cut increasing rate reaches to the maximum value. And with the increase of oil index, water cut when water cut increasing rate reaches to the maximum value gradually decrease. When the value of water oil mobility ratio is large than 10, oil index has little effect on water cut when water cut increasing rate reaches to the maximum value. And with the increase of oil index, water cut when water cut increasing rate reaches to the maximum value gradually increase. With the increase of oil index, the oil relative permeability decrease more and more sharply and water cut increase more and more fast. So water cut when water cut increasing rate reaches to the maximum value gradually increase.

As can be seen from to the maximum value gradually increase.om Figure $5(c)$, there is a linear relationship between recovery percent when water cut increasing rate reaches to the maximum value and oil index. When the value of water oil mobile ratio is less than 10 , oil index has great effect on recovery percent when water cut increasing rate reaches to the maximum value. And with the increase of oil index, recovery percent when water cut increasing rate reaches to the maximum value gradually decrease. With the increase of oil index, the oil relative permeability decrease more and more sharply and water cut increase more and more fast. So water cut increasing rate reaches to the maximum value gradually decrease.

When the value of water oil mobility ratio is large than 10, oil index has little effect on recovery percent when water cut increasing rate reaches to the maximum value. And with the increase of oil index, recovery percent when water cut increasing rate reaches to the maximum value gradually increase. 


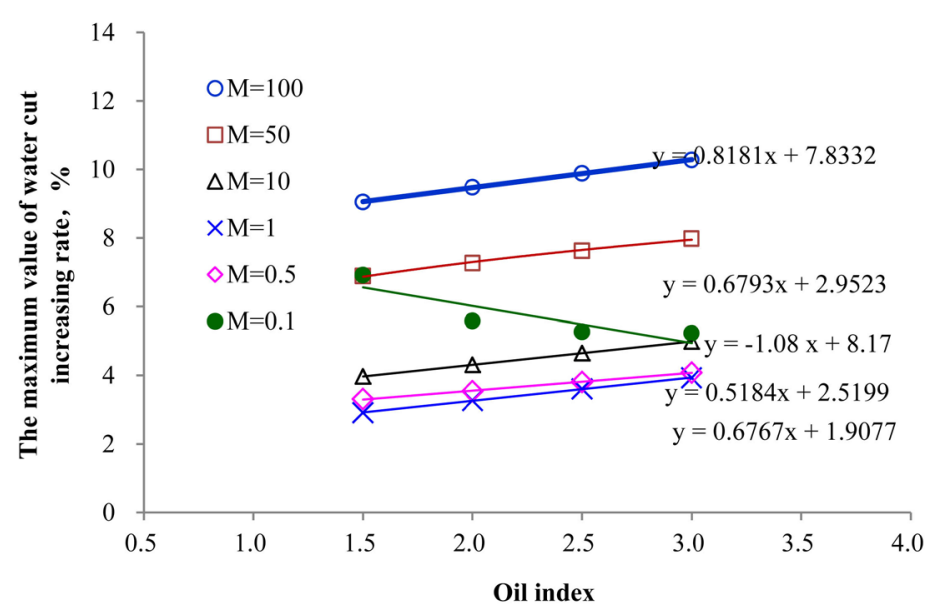

(a)

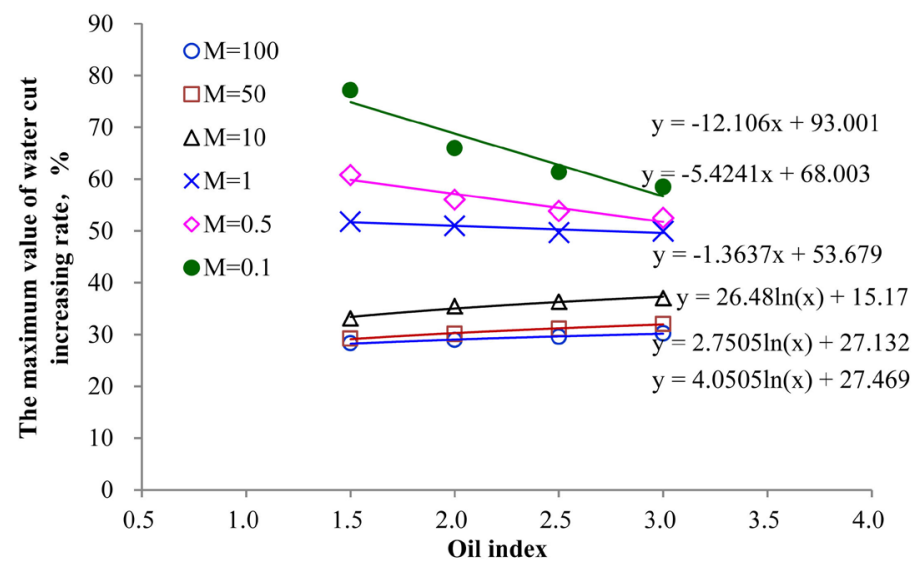

(b)

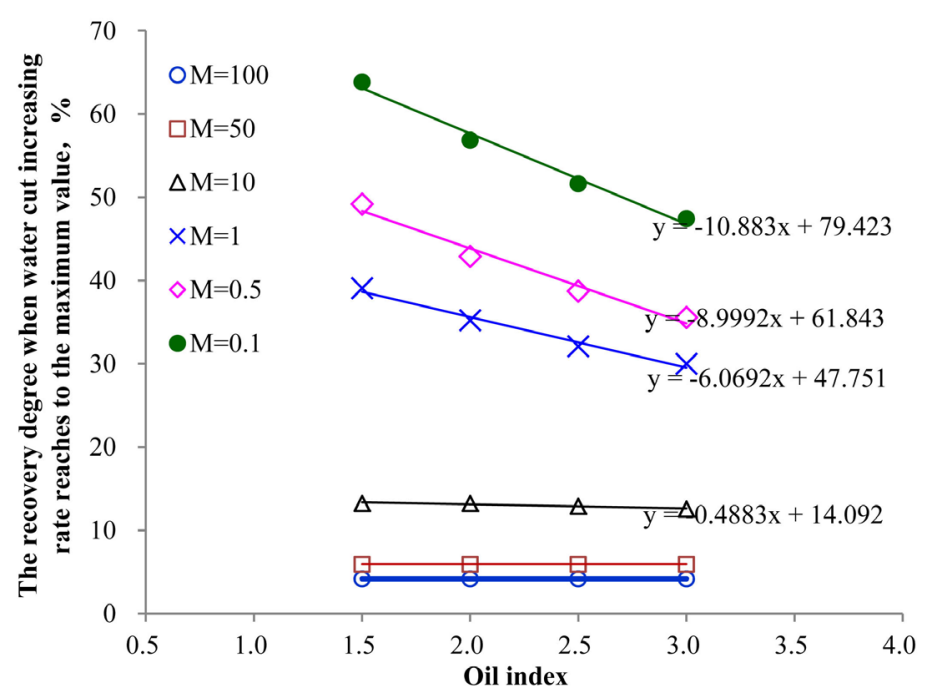

(c)

Figure 5. The end point of water cut increasing rate under the condition of different oil index. (a) Maximum value of water cut increasing rate VS oil index; (b) Water cut when water cut increasing rate reaches to the maximum value VS oil index; (c) Recovery percent when water cut increasing rate reaches to the maximum value VS oil index. 


\subsection{Field Application}

This theoretical curve proposed in this paper has been applied to many water flooding reservoirs of Bohai Bay and the theoretical curve are consistent with field performance. This paper gives an example of SS oilfield to illustrate the application of this model.

SS oilfield belongs to Minghuazhen formation and shallow water delta deposits. The porosity of the reservoir is 0.30 , permeability is $1682 \times 10^{-3} \mu \mathrm{m}^{2}$, formation oil viscosity is $12 \mathrm{mPa} \cdot \mathrm{s}$, formation water viscosity is $0.5 \mathrm{mPa} \cdot \mathrm{s}$, irreducible water saturation is 0.29 , residual oil saturation is 0.22 , water index is 1.67 , oil index is 1.95 , oil relative permeability at irreducible water saturation is 1.00 , water relative permeability at residual oil saturation is 0.31 (Table 2).

According to this method, the theoretical curve between water increasing rate and water cut was established as well as the theoretical curve between water cut increasing rate and recovery percent (Figure 6). As can be seen from Figure 6, the theoretical value are consistent with the field data.

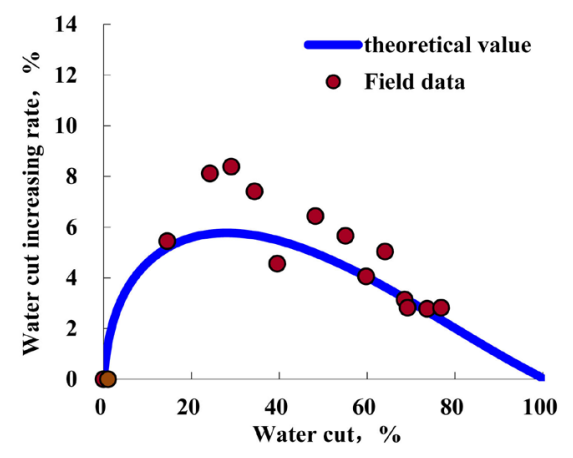

(a)

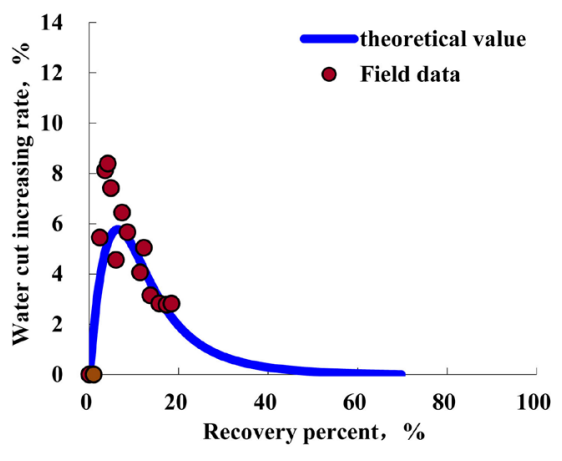

(b)

Figure 6. Theoretical curve and field data of water cut increasing rate. (a) Water cut increasing rate VS water cut; (b) Water cut increasing rate VS recovery percent.

Table 2. The parameters of SS oilfield.

\begin{tabular}{cc}
\hline Parameters & Value \\
\hline Irreducible water saturation, $\mathrm{f}$ & 0.29 \\
Residual oil saturation, f & 0.22 \\
Water index & 1.67 \\
Oil index & 1.95 \\
Porosity & 0.30 \\
Permeability, $0^{-3} \mu^{2}$ & 1682 \\
Formation oil viscosity, mpa·s & 12 \\
Formation water viscosity, mpa·s & 0.5 \\
Well distance, $\mathrm{m}$ & 360 \\
Water relative permeability at residual oil saturation & 0.31 \\
Oil relative permeability at irreducible water saturation & 1.00
\end{tabular}




\section{Conclusions}

Relative permeability curves of Bohai oilfied were analyzed and the average oil index of Bohai oilfied is 2.51. The oil index of Bohai oilfied mostly distributes in the range of 2.0 - 3.0.

The theoretical relationship between oil index and water cut increasing rate is established and three end points of water cut increasing rate curve were proposed. Oil index has a linear relationship with three end points.

When the value of water oil mobile ratio is larger than 1 , with the increase of oil index, maximum value of water cut increasing rate gradually increase. When the value of water oil mobile ratio is less than 10, oil index has great effect on recovery percent when water cut increasing rate reaches to the maximum value as well as water cut when water cut increasing rate reaches to the maximum value.

\section{Conflicts of Interest}

The authors declare no conflicts of interest regarding the publication of this paper.

\section{References}

[1] Okano, H., Pickup, G.E., Christie, M.A., Subbey, S., Sambridge, M. and Monfared, H. (2005) Quantification of Uncertainty in Relative Permeability for Coarse-Scale Reservoir Simulation. Proceedings of the Society of Petroleum Engineers (SPE) Europec/European Association of Geoscientists and Engineers (EAGE) Annual Conference, 13-16 June 2005, Madrid.

[2] Brudine, N.T. (1953) Relative Permeability Calculations from Poresize Distribution Data. Transactions of AIME, 198, 71-78.

[3] Alpak, F.O., Lake, L.W. and Embid, S.M. (1999) Validation of a Modified Carman-Kozeny Equation to Model Two-Phase Relative Permeabilities. Proceedings of the Society of Petroleum Engineers (SPE) Annual Technical Conference and Exhibition, Houston, 3-6 October 1999.

[4] Zhang, J.Q. and Yang, R.F. (2018) Proposing of Theoretical Water Flooding Curve and Discussion on the Relationship between Theoretical Water-Flooding Curve and Production Decline Curve. China Offshore Oil and Gas, 30, 86-92.

[5] Molina, N.N. (1980) A Systematic Approach to the Relative Permeability Problem in Reservoir Simulation. Proceedings of the Society of Petroleum Engineers (SPE) Annual Technical Conference and Exhibition, Dallas, 21-24 September 1980.

[6] Zhang, J.Q., Sun, F.J. and An, G.R. (2011) Study on Incremental Law of Water Cut and Decline Law in Water Drive Oilfield. Petroleum Geology and Recovery Efficiency, 18, 82-85.

[7] Miao, F.F., Zhang, H.Y., Zhang, Y.H., et al. (2015) New Method for Evaluating Effect by Decline Rate Index. Fault-Block Oil \& Gas Field, 22, 353-355.

[8] Liu, Y.X. (2016) A New Calculating Method of Theoretical Decline Law for Water Flooding Sandstone Reservoir. China Offshore Oil and Gas, 28, 79-83.

[9] Zhang, H.Y., Deng, Q., Wang, M.N. and Wang, Y.J. (2018) New Method for Studying the Theoretical Relationship Curve between the Water Cut and Recovery Per- 
cent. Fault-Block Oil \& Gas Field, 25, 345-349.

[10] Wang, S.G., Zhao, G.Z. and Yu, B.J. (2005) Statistical Regularity of Oil Water Relative Permeability in Daqing Oilfield. Petroleum Processing Section, 26, 78-81.

[11] Shang, L.P. (2013) A Study on Natural Decline Rate of Oil Wells. Journal of Yangtze University (Natural Science Edition), 10, 78-80.

[12] Corey, A.T. (1954) The Interrelation between Gas and Oil Relative Permeability. Producers Monthly, 19, 38-41. 